\title{
Cardiopulmonary bypass-induced myocardial reoxygenation injury in pediatric patients with cyanosis
}

\author{
P. Modi, FRCS, H. Imura, MD, M. Caputo, MD, A. Pawade, FRCS, A. Parry, FRCS, \\ G. D. Angelini, FRCS, and M. S. Suleiman, PhD, Bristol, United Kingdom
}

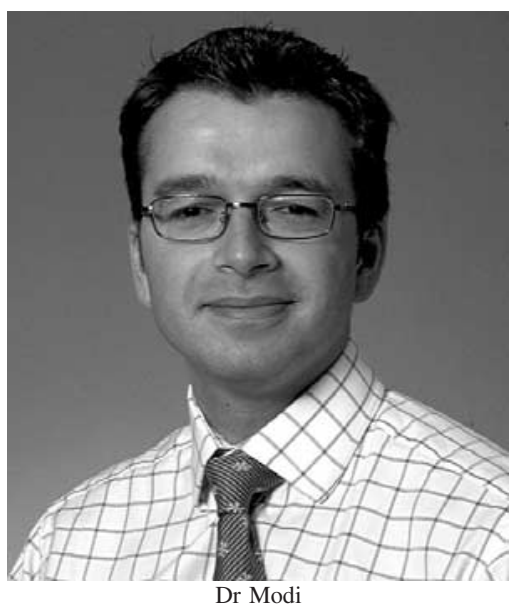

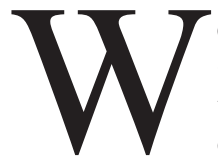

e have recently shown that children with cyanosis (hypoxia) undergoing cardiac operations have worse myocardial reperfusion injuries and clinical outcomes than do those without cyanosis. ${ }^{1}$ Part of the exacerbation may be due to the reintroduction of molecular oxygen on commencement of hyperoxic cardiopulmonary bypass (CPB) before ischemic cardioplegic arrest. Alternatively, CPBinduced reoxygenation injury may render the heart more susceptible to a subsequent period of ischemia. Studies of hypoxemia and reoxygenation in immature piglets have provided evidence for oxygen-mediated myocardial injury as a result of hyperoxemia in the setting of previous cyanosis. ${ }^{2}$ Clinical studies have shown that hyperoxic CPB leads to reduced myocardial antioxidant reserve capacity and higher cerebral dysfunction in infants with cyanosis. However, there is no direct clinical evidence demonstrating intraoperative CPB-induced myocardial reoxygenation injury. This study provides evidence that reoxygenation on $\mathrm{CPB}$ of cyanotic pediatric hearts before ischemic arrest is associated with significant myocardial injury and that longer periods of $\mathrm{CPB}$ induce injury in the hearts of children without cyanosis.

\section{Methods}

Twenty-nine pediatric patients undergoing cardiac surgery were prospectively recruited. All underwent a period of at least 30 minutes of hyperoxic $\mathrm{CPB}$ with the heart beating during the construction of anastomoses to the pulmonary vessels or replace-

From the Bristol Heart Institute, University of Bristol, Bristol Royal Infirmary, Bristol, United Kingdom.

Supported by the British Heart Foundation and the National Heart Research Fund.

Received for publication Dec 10, 2001; accepted for publication Dec 28, 2001.

Address for reprints: M. S. Suleiman, $\mathrm{PhD}$, Bristol Heart Institute, University of Bristol, Bristol Royal Infirmary, Bristol BS2 8HW, United Kingdom (E-mail: M.S.Suleiman@bristol.ac.uk).

J Thorac Cardiovasc Surg 2002;124:1035-6

Copyright (C) 2002 by The American Association for Thoracic Surgery

$0022-5223 / 2002 \$ 35.00+0 \quad \mathbf{1 2 / 5 4 / 1 2 2 5 3 6}$

doi:10.1067/mtc.2002.122536 ment of the pulmonary valve and before ischemic cardioplegic arrest. Bicaval cannulation with ascending aortic return was used for $\mathrm{CPB}$ in all cases. Troponin I was measured in serum samples collected at 1, 10, and 30 minutes of CPB with the ACCESS Immunoassay System (Beckman Instruments Inc, Minneapolis, Minn). Approval was obtained from the local hospital ethics committee and informed consent was obtained from the parents or guardians of all patients.

Statistical analysis. Summary data are presented as counts or as medians and interquartile ranges and compared with the MannWhitney $U$ test. Raw troponin I data were positively skewed, but the distributions became approximately normal and the sampling errors were similar after the raw values were transformed into natural logarithms. A repeated measures analysis of variance was carried out, fitting the main effects of cyanosis and time and the interaction of cyanosis and time. Means and $95 \%$ confidence intervals of the logarithmic data were calculated for each group and time point and then transformed back into natural units (geometric means) for graphic presentation.

\section{Results}

Patients' characteristics are shown in Table 1. Patients with cyanosis were younger, reflecting the differing reasons for surgical intervention. The analysis of variance of the logarithmically transformed data showed highly significant main effects of cyanosis $(\mathrm{F}=20.2, d f=1,81, P<.0001)$ and time $(\mathrm{F}=27.9, d f=2,81$, $P<.0001)$, but no significant interaction $(\mathrm{F}=1.81, d f=2,81$, $P=.18)$. This fitted analysis of variance model implies that the troponin I level increased significantly with time in both groups (by about 3 times between each time point) and that the rate of increase was greater for the infants with cyanosis than for those without (also by about 3 times). The geometric means of the observed data and $95 \%$ confidence intervals, transformed back into natural units, are shown in Figure 1 with fitted values according to the model superimposed.

\section{Discussion}

This study provides direct evidence that cyanotic pediatric hearts sustain an early reoxygenation injury associated with hyperoxic $\mathrm{CPB}$ and that longer periods of $\mathrm{CPB}$ can cause injury to normoxic pediatric hearts. This is likely to contribute to the final tally of injury at the end of surgery and may further increase vulnerability 


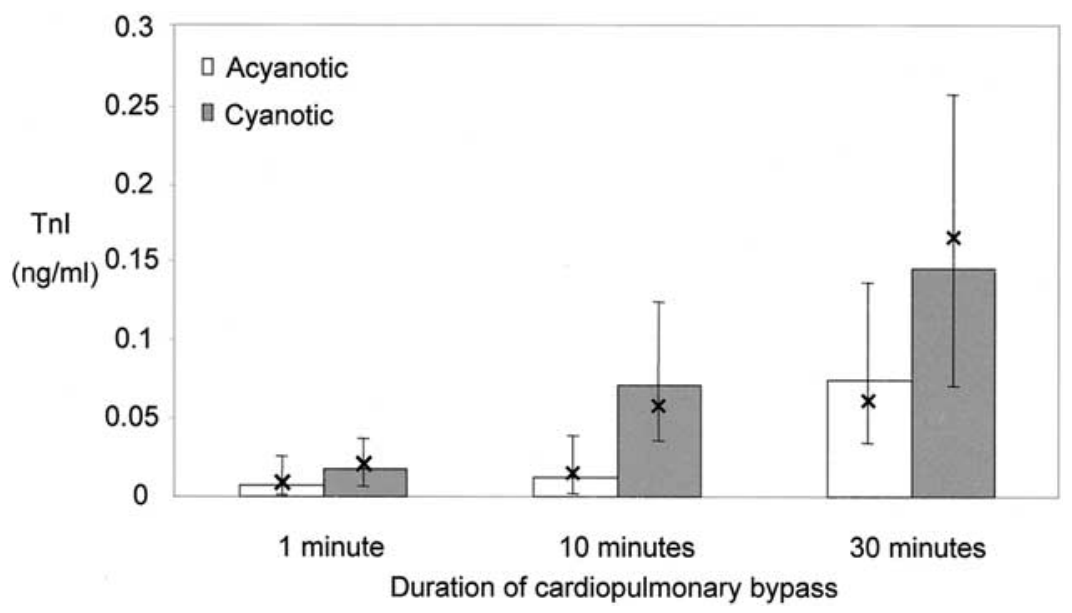

Figure 1. Geometric means (bar heights), 95\% confidence intervals (error bars), and fitted values (crosshairs) of serum troponin I (TnI) in pediatric patients with and without cyanosis measured at different periods of CPB.

\section{TABLE 1. Patient characteristics}

\begin{tabular}{lcc}
\hline & Cyanotic $(\mathbf{n}=\mathbf{2 0})$ & Acyanotic $(\mathbf{n}=\mathbf{9})$ \\
\hline Age (mo) & $11.5(4.5-35.5)$ & $101.0(43.8-174.0)^{*}$ \\
$\begin{array}{l}\text { Body weight (kg) } \\
\text { Sex (M/F) }\end{array}$ & $7.1(5.2-13.1)$ & $18.3(13.1-39.5)^{*}$ \\
$\begin{array}{l}\text { Operation (No.) } \\
\text { Reconstruction of PA }\end{array}$ & $12: 8$ & $6: 3$ \\
$\quad$ with or without RV-PA & 6 & 4 \\
$\quad$ conduit & & \\
$\quad \begin{array}{l}\text { Glenn shunt } \\
\text { Central / modified }\end{array}$ & 6 & 0 \\
$\quad$ Blalock-Taussing shunt & 6 & 0 \\
$\quad \begin{array}{l}\text { Completion of TCPC } \\
\text { Insertion of pulmonary }\end{array}$ & 2 & 1 \\
$\quad$ valve & 0 & 3 \\
$\quad$ Correction of PAPVD & 0 & 1 \\
Hemoglobin (g/dL) & $15.0(14.1-16.1)$ & $13.2(12.5-13.8)^{*}$ \\
Hematocrit (\%) & $0.45(0.40-0.46)$ & $0.38(0.37-0.41)^{*}$ \\
Oxygen saturation (\%) & $80.0(75.0-82.8)$ & $98.0(97.8-98.3)^{*}$ \\
\hline
\end{tabular}

Data are presented as medians (interquartile range) or counts. $P A$, Pulmonary artery; $P A P V D$, partial anomalous pulmonary venous drainage; $R V-P A$, right ventricle to pulmonary artery; $T C P C$, total cavopulmonary connection.

${ }^{*} P<.01$ versus cyanotic.

to subsequent ischemia-reperfusion injury. ${ }^{3}$ The evidence provided offers an explanation of our recent work showing that children with cyanosis have worse myocardial reperfusion injuries and clinical outcome than do those without cyanosis after similar periods of cardioplegic arrest. ${ }^{1}$ The effects of hyperoxia as well as $\mathrm{CPB}$ per se on normoxic myocardium are also consistent with data from normoxic adults and highlight the importance of avoiding lengthy periods of CPB in which the damaging effects of hyperoxia may offset the benefits of reduced mechanical work. Delaying reoxygenation until cardioplegic arrest by starting $\mathrm{CPB}$ with an ambient partial pressure of oxygen has been shown to result in significantly improved myocardial status in immature piglets. ${ }^{4}$ Whether controlled reoxygenation and normoxic CPB will result in reduced morbidity and mortality when used in pediatric cardiac surgery requires further investigation.

The finding that chronic cyanosis preconditions the heart against ischemia-reperfusion injury in experimental models ${ }^{5}$ may not extend to clinical practice. Our work clearly shows that cyanotic hearts sustain more damage both on reoxygenation with $\mathrm{CPB}$ and on reperfusion after cardioplegic arrest than do acyanotic hearts. In conclusion, this study shows that reoxygenation of cyanotic pediatric hearts is associated with significant early myocardial injury and that longer periods of $\mathrm{CPB}$ can induce injury in acyanotic pediatric hearts.

We thank B. Reeves, DPhil, for statistical assistance and M. Ginty for technical assistance.

\section{References}

1. Imura H, Caputo M, Parry A, Pawade A, Angelini GD, Suleiman MS. Age-dependent and hypoxia-related differences in myocardial protection during pediatric open heart surgery. Circulation. 2001;103:1551-6.

2. Morita K, Ihnken K, Buckberg GD, Sherman MP, Young H. Studies of hypoxemic/reoxygenation injury: without aortic clamping IX. Importance of avoiding perioperative hyperoxemia in the setting of previous cyanosis. J Thorac Cardiovasc Surg. 1995;110:1235-44.

3. del Nido RJ, Mickle DA, Wilson GJ, Benson LN, Weisel RD, Coles $\mathrm{JG}$, et al. Inadequate myocardial protection with cold cardioplegic arrest during repair of tetralogy of Fallot. J Thorac Cardiovasc Surg. 1988;95:223-9.

4. Ihnken K, Morita K, Buckberg GD. Delayed cardioplegic reoxygenation reduces reoxygenation injury in cyanotic immature hearts. Ann Thorac Surg. 1998;66:177-82.

5. Baker JE, Curry BD, Olinger GN, Gross GJ. Increased tolerance of the chronically hypoxic immature heart to ischemia-contribution of the KATP channel. Circulation. 1997;95:1278-85. 